\title{
Corrosion Inhibition of Copper-nickel Alloy: Experimental and Theoretical Studies
}

\author{
Anees A. Khadom*, Aprael S. Yaro ${ }^{\dagger}$, Ahmed Y. Musa ${ }^{\ddagger}$, Abu Bakar Mohamad ${ }^{\ddagger}$, and Abdul Amir H. Kadhum \\ Mechanical Engineering Department, College of Engineering, University of Daiyla, Baquba32001, \\ Daiyla governorate, Iraq. E-mail: aneesdr@gmail.com \\ ${ }^{\dagger}$ Chemical Engineering Department, College of Engineering, University of Baghdad, Aljadreaa, \\ Baghdad governorate, Iraq \\ ${ }^{\star}$ Department of Chemical and Process Engineering, Faculty of Engineering and Built Environment, \\ UniversitiKebangsaan Malaysia, Bangi, 43600, Selangor, Malaysia
}

(Received November 23, 2011; Accepted Juen 14, 2012)

\begin{abstract}
The corrosion inhibition of copper-nickel alloy by Ethylenediamine (EDA) and Diethylenetriamine (DETA) in $1.5 \mathrm{M} \mathrm{HCl}$ has been investigated by weight loss technique at different temperatures. Maximum value of inhibitor efficiency was $75 \%$ at $35^{\circ} \mathrm{C}$ and $0.2 \mathrm{M}$ inhibitor concentration EDA, while the lower value was $4 \%$ at $35^{\circ} \mathrm{C}$ and $0.01 \mathrm{M}$ inhibitor concentration DETA. Two mathematical models were used to represent the corrosion rate data, second order polynomial model and exponential model respectively. Nonlinear regression analysis showed that the first model was better than the second model with high correlation coefficient. The reactivity of studied inhibitors was analyzed through theoretical calculations based on density functional theory (DFT). The results showed that the reactive sites were located on the nitrogen (N1, N2 and N4) atoms.
\end{abstract}

Key words: Alloy, Corrosion test, Molecular dynamic, Corrosion

\section{INTRODUCTION}

Acid solutions are often used in industry for cleaning and pickling of metallic structures, processes which are normally accompanied by considerable dissolution of the metal. A useful method to protect metals and alloys in aggressive environments against corrosion is by adding organic or inorganic species to the solution in contact with the surface in order to inhibit the corrosion reaction and hence reduce the corrosion rate. The inhibition effectiveness might be due to the formation of thin layers of metal inhibitor complexes as Trabanelli and his co-workers reported. ${ }^{1}$ Generally, the diminution of the corrosion rate is a result of adsorption which makes, in acidic media, an effective blocking of the active sites of metal dissolution and/or hydrogen evolution. The adsorption requires the existence of attractive forces between the adsorbate and the metal. The principal types of interaction between an organic inhibitor and metal surface are physisorption, chemisorption or both of them. The adsorption of inhibitor is influenced by the nature and surface charge of the metal, the type of aggressive electrolyte, and temperature and the chemical structure of the inhibitor. Indeed, specific interaction between functional groups and the metal surface and heteroatoms like nitrogen, oxygen, sulphur and phosphorus plays an important role in the inhibition process due to the free electron pairs they possess. ${ }^{2}$ Several amines ${ }^{3-5}$ exhibit good inhibitory effect in hydrochloric acid. The present study was undertaken to investigate the copper-nickel alloy corrosion inhibition in $1.5 \mathrm{M}$ hydrochloric acid by Ethylenediamine (EDA) and Diethylenetriamine (DETA). The study was conducted by weight loss method. The thermodynamic parameters of molecule adsorption onto metal surface were determined and the nature of inhibitor adsorption process was also studied and discussed. The molecular structures of the two inhibitors are showed below.

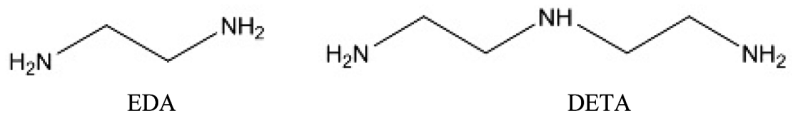

EXPERIMENTAL WORK

The corrosion behavior of copper-nickel alloy, which is used widely in many industrial equipments, was studied using weight loss method in the absence and presence of Ethylenediamine (EDA) and Diethylenetriamine (DETA) in $1.5 \mathrm{MHCl}$ solution at different temperatures $(35,45,55$ 
and $\left.65^{\circ} \mathrm{C}\right)$, and different inhibitor concentrations $(0.01$, $0.05,0.1$ and $0.2 \mathrm{M})$. Ring shape specimen of $\mathrm{Cu}-\mathrm{Ni}$ alloy with dimension $(2.22 \mathrm{~cm})$ outside diameter, $(1.5 \mathrm{~cm})$ width, and $(0.13 \mathrm{~cm})$ thickness, exposing a surface area of about $\left(10 \mathrm{~cm}^{2}\right)$ to corrosive media. Specimens were washed by detergent and flushed by tap water followed by distilled water, degreased by analar benzene and acetone, then annealed in vacuums to $600{ }^{\circ} \mathrm{C}$ for one hour and cooled under vacuum to room temperature. Before each run, specimens of $\mathrm{Cu}-\mathrm{Ni}$ were abraded in sequence using emery paper of grade number $220,320,400$, and 600 then washed by running tap water followed by distilled water then dried by clean tissue, degreased with benzene, dried, degreased with acetone, dried, and finally left in desicater over silica gel. Weighing the specimen was carried out using 4 decimals digital balance and its dimensions were measured with vernier. The metal samples for weight loss runs were completely immersed in $250 \mathrm{~cm}^{3}$ solution of corrodant contained in a conical flask. They were exposed for a period of three days at a desired temperature, acid concentration, and inhibitor concentration. Weight losses were determined in the absence and presence of inhibitors. The data are expressed as mass loss per unit time and per unit area; in the present work the units of corrosion rate were $\mathrm{g} / \mathrm{m}^{2}$.day (gmd). The chemical compositions of Cu-Nialloy were $(0.148 \% \mathrm{Sn}, 0.2 \% \mathrm{Fe}, 0.134 \% \mathrm{Zn}, 0.015 \% \mathrm{Al}$, $0.0003 \% \mathrm{P}, 0.5 \% \mathrm{Sb}, 0.0583 \% \mathrm{~Pb}, 0.0202 \% \mathrm{Si}, 0.017 \% \mathrm{~S}$, $0.0056 \% \mathrm{As}, 10 \% \mathrm{Ni}$, and the remainder is $\mathrm{Cu}$ ).

\section{THEORETICAL CALCULATIONS}

The equilibrium geometries of the EDA and DETA molecules were optimized using energy minimization method implemented in DMol3 model in Material studio v.5.5, a high quality quantum mechanics computer program (available from Accelrys, San Diego, CA). These calculations employed an ab initio, local density functional (LDF) method with a double numericpolarization (DNP) basis set and a Becke-Perdew (BP) ${ }^{6,7}$ The chemical reactivity of the different sites of the molecule was evaluated by Fukui indices, which are defined by ${ }^{5}$

$$
f_{k}^{+}=\left[q_{k}(N+1)-q_{k}(N)\right]
$$

fornucleophilic attack, and

$$
f_{k}^{-}=\left[q_{k}(N)-q_{k}(N-1)\right]
$$

for electrophilic attack, where $q_{k}(N), q_{k}(N-1)$, and $q_{k}(N+$ 1) denote electronic populations of the atom $k$ in neutral, cationic, and anionic systems, respectively. These quan- tities were calculated using Mulliken Population Analysis.

\section{RESULTS AND DISCUSSIONS}

\section{Activation Parameters}

The corrosion rates of $\mathrm{Cu}-\mathrm{Ni}$ alloy in $1.5 \mathrm{M} \mathrm{HCl}$ acid solution as a function of temperature in absence and presence of different inhibitors concentrations are summarized in Table 1 through 36 runs using weight loss technique. The following equations were used to calculate the

Table 1. Effect of temperature and inhibitor concentration on the

\begin{tabular}{|c|c|c|c|c|c|}
\hline Run & Inhibitor & $T\left({ }^{\circ} \mathrm{C}\right)$ & $C(\mathrm{M})$ & $C R$ (gmd) & $I E \%$ \\
\hline 1 & \multirow{4}{*}{ Blank } & 35 & & 12.50 & \\
\hline 2 & & 45 & & 15.87 & \\
\hline 3 & & 55 & & 20.83 & \\
\hline 4 & & 65 & & 30.55 & \\
\hline 5 & \multirow{16}{*}{ EDA } & \multirow{4}{*}{35} & 0.01 & 10.31 & 17 \\
\hline 6 & & & 0.05 & 7.843 & 37 \\
\hline 7 & & & 0.10 & 5.274 & 57 \\
\hline 8 & & & 0.20 & 3.125 & 75 \\
\hline 9 & & \multirow{4}{*}{45} & 0.01 & 12.69 & 20 \\
\hline 10 & & & 0.05 & 9.744 & 38 \\
\hline 11 & & & 0.10 & 6.874 & 56 \\
\hline 12 & & & 0.20 & 4.741 & 70 \\
\hline 13 & & \multirow{4}{*}{55} & 0.01 & 17.74 & 14 \\
\hline 14 & & & 0.05 & 13.32 & 36 \\
\hline 15 & & & 0.10 & 10.55 & 49 \\
\hline 16 & & & 0.20 & 7.875 & 62 \\
\hline 17 & & \multirow{4}{*}{65} & 0.01 & 27.49 & 10 \\
\hline 18 & & & 0.05 & 22.91 & 25 \\
\hline 19 & & & 0.10 & 19.85 & 35 \\
\hline 20 & & & 0.20 & 13.74 & 55 \\
\hline 21 & \multirow{16}{*}{ DETA } & \multirow{4}{*}{35} & 0.01 & 12.375 & 4 \\
\hline 22 & & & 0.05 & 12 & 8 \\
\hline 23 & & & 0.10 & 11.51 & 10 \\
\hline 24 & & & 0.20 & 10.625 & 15 \\
\hline 25 & & \multirow{4}{*}{45} & 0.01 & 14.99 & 5 \\
\hline 26 & & & 0.05 & 13.71 & 13 \\
\hline 27 & & & 0.10 & 13.01 & 15 \\
\hline 28 & & & 0.20 & 11.27 & 29 \\
\hline 29 & & \multirow{4}{*}{55} & 0.01 & 19.44 & 6 \\
\hline 30 & & & 0.05 & 16.98 & 18 \\
\hline 31 & & & 0.10 & 14.58 & 30 \\
\hline 32 & & & 0.20 & 12.05 & 42 \\
\hline 33 & & \multirow{4}{*}{65} & 0.01 & 27.19 & 11 \\
\hline 34 & & & 0.05 & 23.22 & 24 \\
\hline 35 & & & 0.10 & 17.72 & 42 \\
\hline 36 & & & 0.20 & 12.22 & 60 \\
\hline
\end{tabular}
corrosion of $\mathrm{Cu}-\mathrm{Ni}$ alloy in $1.5 \mathrm{M} \mathrm{HCl}$ acid solution 
weight loss corrosion rate and inhibitor efficiency respectively:

$$
\begin{aligned}
& C R=\frac{\text { weight loss }(\mathrm{g})}{\operatorname{area}\left(\mathrm{m}^{2}\right) \times \text { time (day) }} \\
& I E \%=\frac{C R_{\text {uninibit }}-C R_{\text {inhibit }}}{C R_{\text {uninibit }}} \times 100
\end{aligned}
$$

Where $C R_{\text {uninhibit }}$ and $C R_{\text {inhibit }}$, are the corrosion rates in absence and presence of inhibitors, respectively. Thermodynamic parameters of the corrosion reaction, namely activation energy $E_{a c t}$, entropy $\Delta S_{a c t}$ and enthalpy $\Delta H_{a c t}$ of activation were calculated using Arrhenius equation (Eq. 5) and its alternative formulation called transition state equation (Eq. 6). From the corrosion rate data at different temperatures in absence and presence of Ethylenediamine (EDA) and Diethylenetriamine (DETA) as corrosion inhibitors, Arrhenius and transition state plots were obtained. Activation energies were calculated from the Arrhenius plots, which represent the relationship between $\log (C R)$ and the reciprocal of absolute temperature: ${ }^{8}$

$$
\log C R=\log A-\frac{E_{a c t}}{2.303 R T}
$$

While the transition state equation can be defined as:

$$
C R=\frac{R T}{N h} \exp \left(\frac{\Delta S_{a c t}}{R}\right) \exp \left(-\frac{\Delta H_{a c t}}{R T}\right)
$$

Where $A$ is the frequency factor, $T$ is the absolute temperature, $R$ is the universal gas constant, $h$ is Plank's constant, and $N$ is Avogadro's number. The values of entropy of activation $\Delta S_{\text {act }}$ and of the enthalpy $\Delta H_{\text {act }}$ of activation were obtained by drawing of Eq. 6 as $\log (C R / T)$ vs $(1 / T)$. Figs. 1 and 2 show Arrhenius and transition state plots for

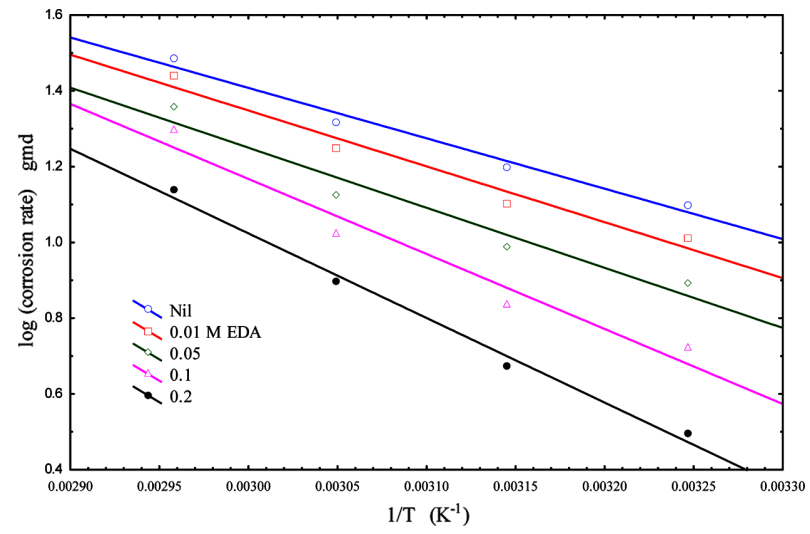

Fig. 1. Arrhenius Plot of $\mathrm{Cu}-\mathrm{Ni}$ Alloy in $1.5 \mathrm{M} \mathrm{HCl}$ Containing Various Concentration of EDA.

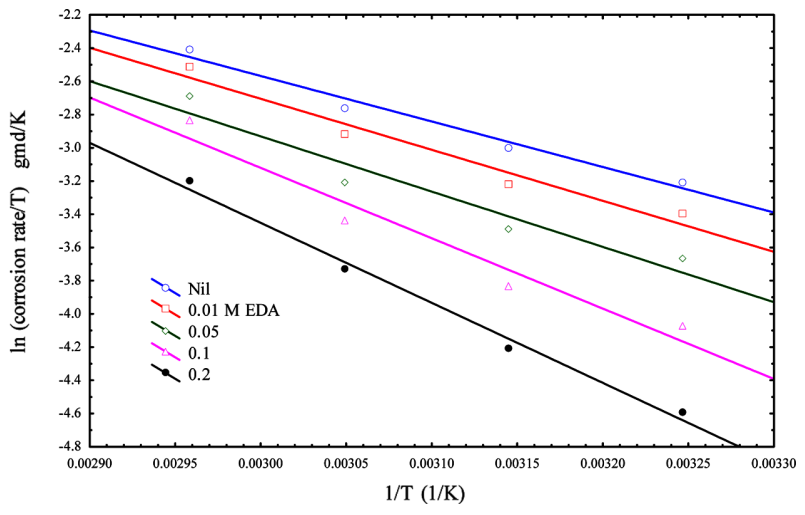

Fig. 2. Transition state $\mathrm{Plot}$ of $\mathrm{Cu}-\mathrm{Ni}$ Alloy in $1.5 \mathrm{M} \mathrm{HCl}$ Containing Various Concentration of EDA.

EDA at different conditions, similar plots were obtained for DETA but do not appear in this paper. The values of activation parameters were listed in Table 2. In case of EDA the values of $E_{a c t}$ and $\Delta H_{\text {act }}$ were higher as compared with uninhibited acid. This means that the corrosion reaction in presence of the inhibitor needs more energy to occur. While in the case of DETA the activation energy $E_{\text {act }}$ and activation enthalpy $\Delta H_{\text {act }}$ for an uninhibited acid were higher than in inhibited acid. The decrease in the value of activation energy appears to be paradoxical. However, Khadom and Yaro ${ }^{9}$ attributed this to increased coverage of the metal surface by the inhibitor at higher temperatures and also suggested that the rate of formation of the chemisorbed passive film may be greater than its rate of dissolution at higher temperatures. El-Anadouli et al. ${ }^{10}$ obtained values of activation energy for the corrosion of metal in acidic media in absence and presence of some inhibitors. They found that some inhibitors in the corrosive medium modify the kinetics of corrosion reaction by offering alternate reaction paths with lower activation energies. The value of $E_{\text {act }}$ for copper-nickel alloy corrosion in uninhibited hydrochloric acid solution $\left(21.71 \mathrm{~kJ}^{\mathrm{mol}}{ }^{-1}\right)$ is in the same order of magnitude of some literature data for copper alloy in some acid solutions. ${ }^{11,12}$ Table 2, shows that all the values of $A$ are lower than that of the blank, which is an advantage for inhibiting the corrosion rate of metals. It is well known that the increase in $A$ elevates the corrosion rate of metal. ${ }^{12}$ As observed above, for all cases $E_{a c t}>\Delta H_{\text {act }}$ by a value which approximately equal to $R T$. From the thermodynamic and kinetic point of view, the unimolecular reactions are characterized by following the equation $^{13}$

$$
E_{a c t}-\Delta H_{a c t}=R T
$$


Table 2. Activation parameters for $\mathrm{Cu}-\mathrm{Ni}$ alloy corrosion reaction in inhibited $\mathrm{HCl}$

\begin{tabular}{|c|c|c|c|c|c|}
\hline Inhibitor & $C(\mathrm{M})$ & $A\left(\mathrm{~g} / \mathrm{m}^{2}\right.$.day $)$ & $E_{\text {act }}(\mathrm{kJ} / \mathrm{mol})$ & $\Delta H_{a c t}(\mathrm{~kJ} / \mathrm{mol})$ & $\Delta S_{\text {act }}(\mathrm{kJ} / \mathrm{mol} . \mathrm{K})$ \\
\hline & 0 & 53333.5 & 21.71 & 19.14 & -0.162 \\
\hline \multirow{4}{*}{ EDA } & 0.01 & 49928.3 & 21.514 & 26.5 & -0.045 \\
\hline & 0.05 & 44946.9 & 22.206 & 25.71 & -0.0495 \\
\hline & 0.10 & 432713.1 & 29.06 & 33.5 & -0.028 \\
\hline & 0.20 & 11494.4 & 38.77 & 42.52 & 0.0165 \\
\hline \multirow{4}{*}{ DETA } & 0.01 & 19833.5 & 19.215 & 16.82 & -0.17 \\
\hline & 0.05 & 3476.9 & 14.78 & 12.363 & -0.184 \\
\hline & 0.10 & 555.9 & 10.056 & 7.285 & -0.201 \\
\hline & 0.20 & 83.4 & 5.354 & 2.659 & -0.217 \\
\hline
\end{tabular}

The value of $\Delta S_{a c t}$ is negative in absence of inhibitors. In absence of inhibitors the Transition State of the rate-determining recombination step represents a more orderly arrangement relative to the initial state, and hence, a negative value for $\Delta S_{\text {act }}$ is obtained. It is still negative in presence of inhibitors but its magnitude decreases with increasing concentrations of inhibitors. This was because these compounds inhibited acid dissolution of metal by simple blocking on the surface without changing the mechanism of corrosion process. ${ }^{14}$ According to Khadom et al. ${ }^{14}$ the corrosion of metals in neutral or acidic solution is cathodically controlled by the hydrogen evolution reaction which occurs in two steps,

$$
\begin{aligned}
& H^{+}+e \rightarrow H_{a d s} \\
& H^{+}+H_{a d s} \rightarrow H_{2}
\end{aligned}
$$

The rate-determining step for the hydrogen evolution reaction is the recombination of adsorbed hydrogen atoms to form hydrogen molecules (Eq. 8). In free acid solution the transition state of the rate determining recombination step represents a more orderly arrangement relative to initial state and hence a negative value for the entropy of activation is obtained. In presence of inhibitors, the entropy of activation still has a negative value but its magnitude decreases with increase of the inhibitor concentration in the case of EDA. In the presence of this compound, the recombination of adsorbed hydrogen atoms to form hydrogen molecules is hindered. In the case of DETA, the values of $\Delta S_{\text {act }}$ are higher. So, this may be due to the new path of reaction, which reduced the values of $E_{\text {act }}$ and $\Delta H_{\text {act }}$, respectively. At the same time this path may have a more random recombination step.

\section{Adsorption Parameters}

Surface coverage $(\Theta)$ data are very useful while considering inhibitor adsorption characteristics. The primary step in inhibitor action in the acid solution generally is agreed to be its adsorption on the metal surface. This involves the assumption that corrosion reactions are prevented from occurring over the area (or at active sites) on a metal surface that is covered by adsorbed inhibitor species, whereas these corrosion reactions normally occurred on inhibitor-free areas. ${ }^{15}$ Accordingly, the fraction of surface covered with inhibitor species $(\theta=I E \% / 100)$ can follow as a function of inhibitor concentration and solution temperature. When the fraction of surface covered is determined as a function of the concentration at constant temperature, adsorption isotherm could be evaluated at equilibrium condition. Fraction dependence of surface covered $\theta$ on the concentration $C$ of the inhibitor was tested graphically by fitting it to Langmuir's isotherm, which assumes that the solid surface contains a fixed number of adsorption sites and each site holds one adsorbed species. Eq. 10 and Fig. 3 show linear plots when drawn as $C / \theta$ versus $C$, suggesting that adsorption is in line with Langmuir's isotherm:

$$
\frac{C}{\theta}=\frac{1}{K_{\text {Langmuir }}}+C
$$

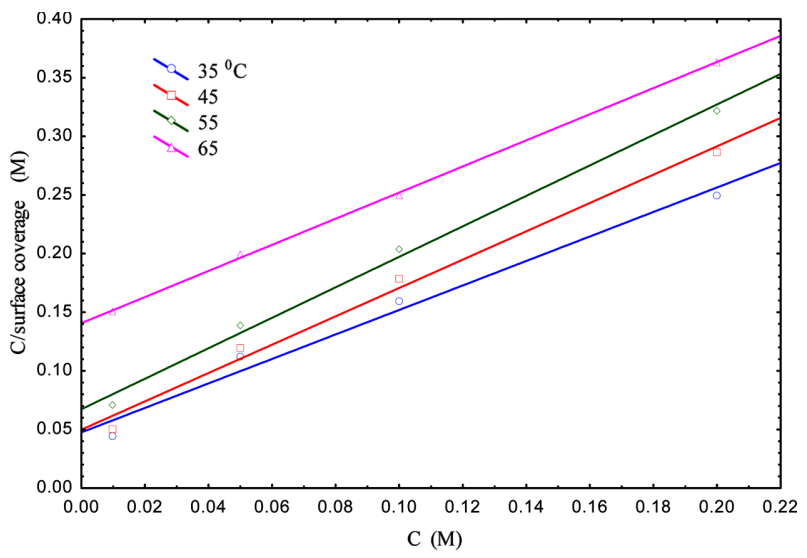

Fig. 3. Langmuir adsorption isotherm of EDA on metal surface. 
Table 3. Adsorption parameters for corrosion inhibition of $\mathrm{Cu}-\mathrm{Ni}$ alloy in $1.5 \mathrm{M} \mathrm{HCl}$

\begin{tabular}{ccccccccc}
\hline Inhibitor type & $T\left({ }^{\circ} \mathrm{C}\right)$ & $K_{\text {Langmuir }}\left(\mathrm{M}^{-1}\right)$ & $\Delta G_{\text {ads }}^{o}(\mathrm{~kJ} / \mathrm{mol})$ & $\mathrm{R}$ & $K_{\text {Kinetic }}\left(\mathrm{M}^{-1}\right)$ & $y$ & $\Delta G^{o}{ }_{\text {ads }}(\mathrm{kJ} / \mathrm{mol})$ & $\mathrm{R}$ \\
\hline \multirow{6}{*}{ EDA } & 35 & 9.1953 & -12.880 & 0.9575 & 9.6160 & 0.925 & -12.996 & 0.9715 \\
& 45 & 10.998 & -13.771 & 0.9736 & 9.1352 & 0.793 & -13.282 & 0.9789 \\
& 55 & 9.0150 & -13.664 & 0.9851 & 6.4307 & 0.802 & -12.742 & 0.9950 \\
& 65 & 9.1141 & -13.712 & 0.9887 & 6.0316 & 0.772 & -12.888 & 0.9333 \\
\hline \multirow{6}{*}{ DETA } & 35 & 3.61095 & -9.104 & 0.9552 & 0.2063 & 0.512 & -1.775 & 0.99248 \\
& 45 & 4.64265 & -10.087 & 0.9797 & 1.0936 & 0.631 & -6.241 & 0.95252 \\
& 55 & 6.08703 & -11.156 & 0.9321 & 4.0545 & 0.833 & -10.011 & 0.99284 \\
& 65 & 8.1225 & -12.346 & 0.9431 & 7.1176 & 0.889 & -12.131 & 0.9348 \\
\hline
\end{tabular}

Where $\mathrm{C}$ is inhibitor concentration, $K_{\text {Langmuir }}$ adsorptive equilibrium constant representing the degree of adsorption (i.e., the higher value of $K_{\text {Langmuir }}$ indicates that the inhibitor is strongly adsorbed on the metal surface). As shown in Table 3 , the value of $K_{\text {Langmuir }}$ was obtained from the reciprocal of intercept of Langmuir plot line, and the correlation coefficients, $\mathrm{R}$, of this line is near unity means that each inhibitor molecule occupies one active site on metal surface. It is a known fact that $K_{\text {Langmuir }}$ denotes the strength between adsorbate and adsorbent. Large values of $K_{\text {Langmuir }}$ imply more efficient adsorption and consequently better inhibition efficiency. ${ }^{16}$ It is clear from Table 3 that values of $K_{\text {Langmuir }}$ are low, indicating weak interaction between inhibitors and metal surface. It seems, therefore, that electrostatic interaction (physisorption) among inhibitor molecules existing as cations should prevail over molecular interaction, and this often results in strong interactions (chemisorption). ${ }^{17}$ The equilibrium constant of adsorption $K_{\text {Langmuir }}$ is related to the standard adsorption free energy $\left(\Delta G_{a d s}^{o}\right)$ by the following equation: ${ }^{18}$

$$
K=\frac{1}{55.5} \exp \left(-\frac{\Delta G_{a d s}^{o}}{R T}\right)
$$

Where, 55.5 is water concentration in solution expressed in molar (M), R is gas constant, and $\mathrm{T}$ absolute temperature. From Table 3, the average value of standard adsorption free energy $\left(\Delta G_{\text {ads }}^{o}\right)$ was $-13.44 \mathrm{kH} . \mathrm{mol}^{-1}$ for EDA and $-10.11 \mathrm{~kJ} \cdot \mathrm{mol}^{-1}$. The negative value of $\Delta G_{\text {ads }}^{o}$ ensures spontaneity of the adsorption process and stability of adsorbed layer on metal surface. Generally, value of $\Delta G_{a d s}^{o}$ up to $-20 \mathrm{~kJ} . \mathrm{mol}^{-1}$ is consistent with electrostatic interaction between the charged molecules and the charged metal (physisorption) while those around $-40 \mathrm{~kJ} . \mathrm{mol}^{-1}$ or higher are associated with chemisorptions as a result of sharing or transferring of electrons from organic molecules to metal surface to form a coordinate type of bond $[18,19]$, while other researchers suggested that the range of $\Delta G_{a d s}^{o}$ of chemical adsorption processes for organic inhibitor in aqueous media lies between -21 to $-42 \mathrm{~kJ} \cdot \mathrm{mol}^{-1} \cdot{ }^{15}$ One can see that the calculated $\Delta G_{a d s}^{o}$ values are less than $20 \mathrm{~kJ} \mathrm{~mol}^{-1}$, indicating that the adsorption mechanism of EDA and DETA on $\mathrm{Cu}-\mathrm{Ni}$ surface in $1.5 \mathrm{M} \mathrm{HCl}$ solution was typical of physisorption (Table 3). The adsorption on the corroding surfaces never reaches the real equilibrium and tends to reach an adsorption steady state. However, when the corrosion rate is sufficiently small, the adsorption steady state has a tendency to become a quasi-equilibrium state. In this case, it is reasonable to consider the quasiequilibrium adsorption in thermodynamic way using the appropriate equilibrium isotherms. It is essential to know the mode of adsorption and the adsorption isotherm that can give valuable information on the interaction of inhibitor and metal surface. Some researchers have looked into the action of an adsorptive inhibitor from a purely mechanistic kinetic point of view. ${ }^{20}$ This relation can be expressed as follow, $\theta / 1-\theta=K^{\prime} C^{y}$, or this equation can be written in linear form as;

$$
\ln \left(\frac{\theta}{1-\theta}\right)=\ln K^{\prime}+y \ln C
$$

Where $K^{\prime}$ is a constant, and $y$ is the number of inhibitor molecules occupying one active site. A plot of $\ln (\theta / 1-\theta)$ vs. $\ln C$ gives a straight line of slop y and intercept of $\ln K^{\prime}$ (Fig. 4). Equilibrium constant corresponding to adsorption isotherm is given by, $K_{\text {kinetic }}=K^{1 / y}$. Values of $\mathrm{y}>1$ imply the formation of multilayer of inhibitor on the surface of metal. Values of $y<1$ mean the molecules of a given inhibitor will occupy more than one active site. As shown in Table 3, the kinetic-thermodynamic model data were in a good agreement with that obtained by Langmuir adsorption isotherm model. The value of $y$ was lower than unity indicating the formation of monolayer on the metal surface, and the values of $K_{\text {kinetic }}$ were comparable. Experimental results obtained in this study were further fitted into Dubinin-Radushkevich isotherm model (D-RIM). This model was initially used to distinguish between 


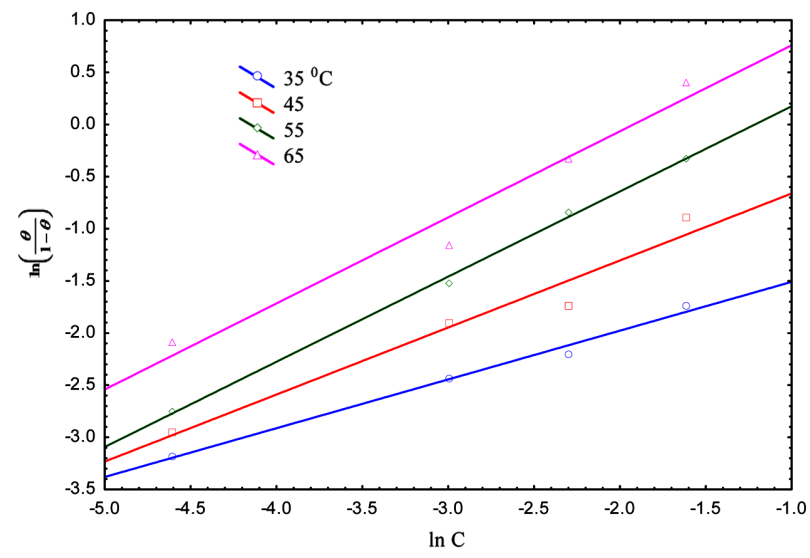

Fig. 4. Kinetic - thermodynamic isotherm for adsorption of DETA on metal surface.

physical and chemical adsorption for removal of some pollutants from aqueous solutions by adsorption on various adsorbents. ${ }^{21}$ Recently, Noor ${ }^{22}$ has applied this model in explaining the mechanism of adsorption of corrosion inhibitor onto a metal surface in acidic medium. The equation for the isotherm model can be expressed as:

$$
\ln \theta=\ln \theta_{\max }-a \delta^{2}
$$

where $\theta_{\max }$ is the maximum surface coverage and $\sigma$ (Polany potential) can be correlated as:

$$
\delta=R T \ln \left(1+\frac{1}{C}\right)
$$

where $R$ is the universal gas constant, $T$ is the absolute temperature and $C$ is the concentration of the inhibitor. The constant a gives the mean adsorption energy, $E$, which is the transfer energy of $1 \mathrm{~mol}$ of adsorbate from infinity (bulk solution) to the surface of the adsorbent.

$$
E=\frac{1}{\sqrt{2 a}}
$$

The magnitude of $E$ gives information about the type of adsorption. Values of $E$ less than $8 \mathrm{~kJ} / \mathrm{mol}$ indicates physical adsorption. ${ }^{22}$ Fig. 5 shows the relationship between $\ln \theta$ and $\sigma^{2}$ for the corrosion rate data at different temperatures and the corresponding parameters from the regression analysis are listed in Table 4. It is clear from the table that the numerical values of $E$ reflect physical adsorption mechanism. The values of $\theta_{\max }$ (maximum surface coverage) for the two inhibitors are in good agreement which further corroborates the results obtained for the inhibition efficiency values.

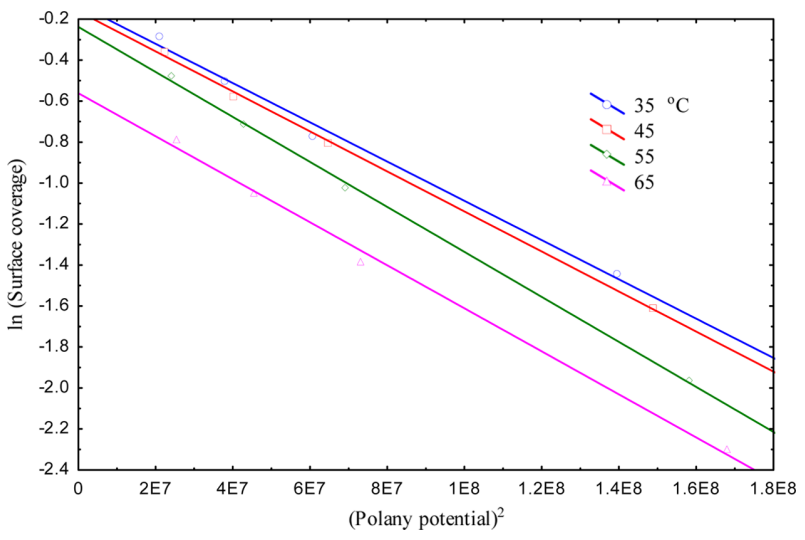

Fig. 5. Dubinin-Radushkevich isotherm model for EDA.

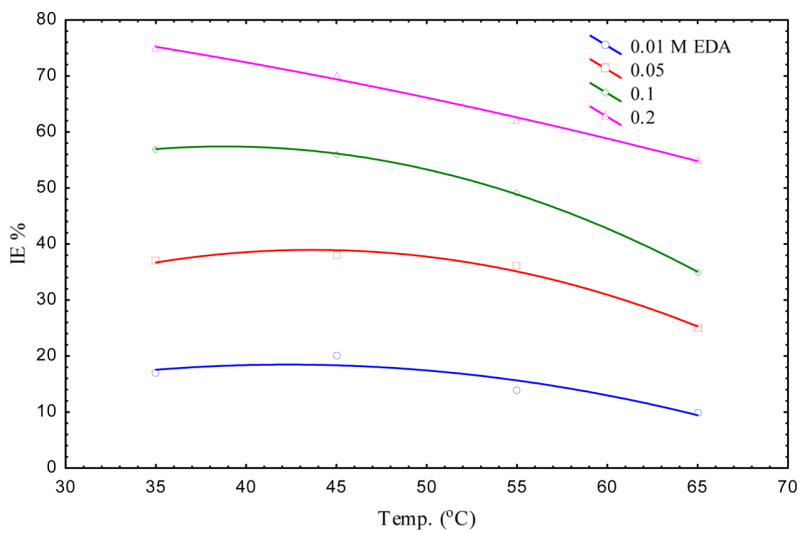

Fig. 6. Effect of temperature on inhibitor efficiency of EDA.

Table 4. Adsorption parameters for corrosion inhibition of $\mathrm{Cu}-\mathrm{Ni}$ alloy in $1.5 \mathrm{M} \mathrm{HCl}$ by Dubinin-Radushkevich isotherm model

\begin{tabular}{ccccc}
\hline Inhibitor type & $\mathrm{T}\left({ }^{\circ} \mathrm{C}\right)$ & $\theta_{\max }$ & $\mathrm{a}\left(\mathrm{mol}^{2} \mathrm{~kJ}^{-1}\right)$ & $\mathrm{E}\left(\mathrm{kJ} \cdot \mathrm{mol}^{-1}\right)$ \\
\hline \multirow{4}{*}{ EDA } & 35 & 0.8 & 0.05 & 3.16 \\
& 45 & 0.8 & 0.07 & 2.67 \\
& 55 & 0.7 & 0.09 & 2.36 \\
& 65 & 0.7 & 1.01 & 0.71 \\
\hline \multirow{4}{*}{ DETA } & 35 & 0.4 & 0.38 & 1.14 \\
& 45 & 0.5 & 0.29 & 1.32 \\
& 55 & 0.4 & 0.21 & 1.56 \\
& 65 & 0.7 & 0.12 & 2.02 \\
\hline
\end{tabular}

\section{Effect of Temperature on Inhibitor Efficiency}

Table 1 shows the effect of temperature on the performance of the inhibitor. The addition of inhibitors reduces the corrosion rate at different temperatures. In the case of EDA, as shown in Fig. 5 the values of inhibitor efficiency decreased slightly with temperature raise, while in the case of DETA, as shown in Fig. 6, the inhibitor efficiency slightly increased with increasing in temperature, the maximum value was $60 \%$ at $0.2 \mathrm{M}$ inhibitor concentra- 
tion, and $65^{\circ} \mathrm{C}$ and the minimum value was $4 \%$ at $0.01 \mathrm{M}$ inhibitor concentration and $35^{\circ} \mathrm{C}$.

\section{Combined Influence of Temperature and Inhibitor Concentration on the Corrosion Rate}

The experimental corrosion rate results in uninhibited and inhibited $1.5 \mathrm{M} \mathrm{HCl}$ acid as a function of temperature and inhibitor concentration are given in Table 1. Our previous models ${ }^{12}$ can be suggested again to represent the corrosion rate data. Second order polynomial model was used to represent the temperature and inhibitor concentration effects as follows:

$$
\begin{aligned}
& Y=a_{1}+a_{2} X_{1}+x_{3} X_{1}^{2}+a_{4} X_{1} X_{2}+a_{5} X_{2}+a_{6} X_{2}^{2} \\
& Y=a_{7}\left(\frac{1}{X_{1}}\right)^{a_{8}} \exp \left(-\frac{a_{9}}{X_{2}}\right)
\end{aligned}
$$

where; $Y$ : Corrosion Rate (gmd), $X_{1}$ : Inhibitor Concentration (M) $X_{2}$ : Absolute Temperature $(K)$ and, $a_{1}, a_{2}, a_{3}$ $a_{9}$ : are constants. These constants were evaluated by using non-linear estimation regression based on LevenbergMarquardt method. Eq. 16 used as a first model $\left(M_{1}\right)$ to represent the results and yield the following equation for EDA (correlation coefficient $\left.\mathrm{R}^{2}=0.9988\right)$ and DETA $\left(\mathrm{R}^{2}=\right.$ $0.9945)$ respectively:

$$
\begin{aligned}
Y= & 880.15+96.71 X_{1}+255.41 X_{1}^{2}-0.59 X_{1} X_{2} \\
& -6.11 X_{2}+0.01 X_{2}^{2} \\
Y= & 380.96+420.66 X_{1}+66.44 X_{1}^{2}-1.43 X_{1} X_{2} \\
& -3.33 X_{2}+0.005 X_{2}^{2}
\end{aligned}
$$

While, Eq. 17 used as a second model $\left(M_{2}\right)$ to represent the results and yield the following equation for EDA (correlation coefficient $\left.R^{2}=0.9788\right)$ and DETA $\left(R^{2}=0.9368\right)$

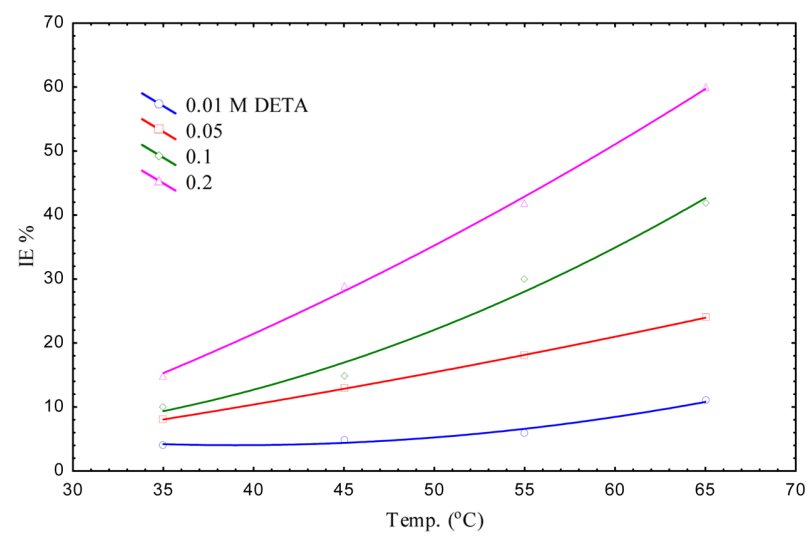

Fig. 7. Effect of temperature on inhibitor efficiency of DETA.

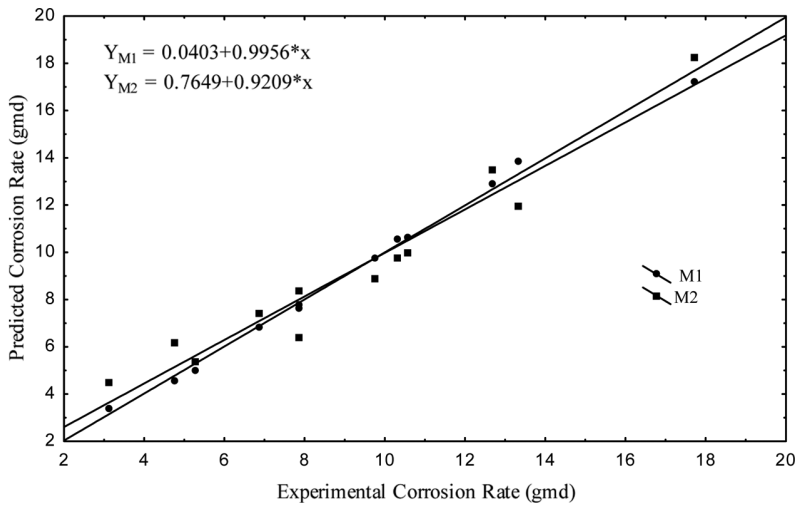

Fig. 8. The deviation of the Two Suggested Models from the Corrosion Rate data of $\mathrm{Cu}-\mathrm{Ni}$ Alloy in Presence of EDA in 1.5 $\mathrm{M} \mathrm{HCl}$.

respectively:

$$
\begin{aligned}
& Y=90448.61\left(\frac{1}{X_{1}}\right)^{-0.27} \exp \left(-\frac{3147.43}{X_{2}}\right) \\
& Y=1700.37\left(\frac{1}{X_{1}}\right)^{-0.11} \exp \left(-\frac{1633.1}{X_{2}}\right)
\end{aligned}
$$

Figs. 7 and 8 show these models against the experimental corrosion rate data. Also it could be seen the high fitting between experimental and predicted corrosion rates. The best fitting obtained with model $M_{1}$.

\section{Mechanism of Inhibition}

The adsorption of inhibitors at metal/solution interfaces can markedly change the corrosion resisting properties of metals. ${ }^{23}$ The efficiency of organic molecules as good corrosion inhibitors mainly depends on their adsorption ability on the metal surface. So, the investigation of the relation between corrosion inhibition and adsorption is of great importance. The cathodic reaction that occurs on the copper alloy surface in $1.5 \mathrm{M} \mathrm{HCl}$ is the oxygen reduction, Since $\mathrm{Cu}$ is nobler than $\mathrm{H}^{+}$in the electromotive series, and a cathodic reaction other than the displacement of $\mathrm{H}^{+}$must account for metal dissolution. This is readily available in terms of $\mathrm{O}_{2}$ reduction from solution. ${ }^{24}$ Anodic dissolution of copper in chloride media has been studied extensively. ${ }^{25-29}$ The accepted anodic reaction is the dissolution of copper through oxidation of $\mathrm{Cu}$ to $\mathrm{Cu}^{+}$:

$$
\mathrm{Cu} \rightarrow \mathrm{Cu}+e
$$

Then $\mathrm{Cu}^{+}$reacts with chloride ion from the solution to form $\mathrm{CuCl}$ :

$$
\mathrm{Cu}^{+}+\mathrm{Cl}^{-} \rightarrow \mathrm{CuCl}
$$




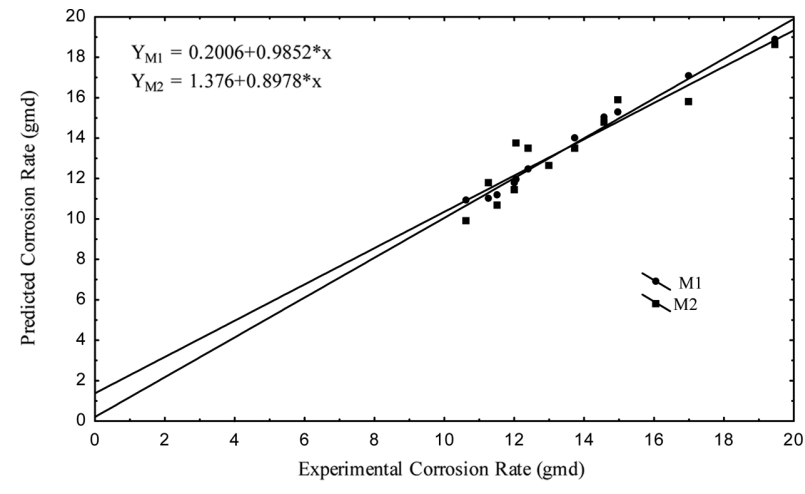

Fig. 9. The deviation of the Two Suggested Models from the Corrosion Rate data of $\mathrm{Cu}-\mathrm{Ni}$ Alloy in Presence of DETA in $1.5 \mathrm{M} \mathrm{HCl}$.

Insoluble $\mathrm{CuCl}$ precipitates on the copper surface. The $\mathrm{CuCl}$ species has poor adhesion, is unable to produce enough protection for the copper surface, and transforms to the sparingly soluble cuprous chloride complex, $\mathrm{CuCl}_{2}^{-30}$

$$
\mathrm{CuCl}+\mathrm{Cl}^{-} \rightarrow \mathrm{CuCl}_{2}^{-}
$$

It has also been reported that the $\mathrm{CuCl}_{2}{ }_{2}$ adsorbed on the surface dissolves by further oxidation: ${ }^{28}$

$$
\mathrm{CuCl}_{2, a d s}^{-} \rightarrow \mathrm{Cu}^{++}+2 \mathrm{Cl}^{-}+e
$$

It is reported that the anodic dissolution of copper in the acidic chloride solution is controlled by both electro dissolution of copper and diffusion of $\mathrm{CuCl}_{2}^{-}$to the solution bulk. ${ }^{28,30}$ The cathodic corrosion reaction in an aerated acidic chloride solution is:

$$
4 \mathrm{H}^{+}+\mathrm{O}_{2}+4 e^{-} \rightarrow 2 \mathrm{H}_{2} \mathrm{O}
$$

The total corrosion reaction of copper in acidic chloride solutions is as follows:

$$
2 \mathrm{Cu}+4 \mathrm{H}^{+}+4 \mathrm{Cl}^{-}+\mathrm{O}_{2} \rightarrow 2 \mathrm{Cu}^{2+}+4 \mathrm{Cl}^{-}+2 \mathrm{H}_{2} \mathrm{O}
$$

It is clear from the polarization experiments that the presence of inhibitors decreases the corrosion rate. In acidic solutions, organic inhibitors exists as cationic species $\mathrm{R}^{+}{ }^{31}$ The protonated amines can be adsorbed on the metal surface on previously adsorbed chloride ions, since organic compounds with heteroatoms of $\mathrm{N}$ and $\mathrm{S}$ are able to adsorb on the metal surface even at high concentration of chloride ions. ${ }^{32}$ Fig. 10 shows the three suggested inhibition mechanisms. In model I, at low concentrations,

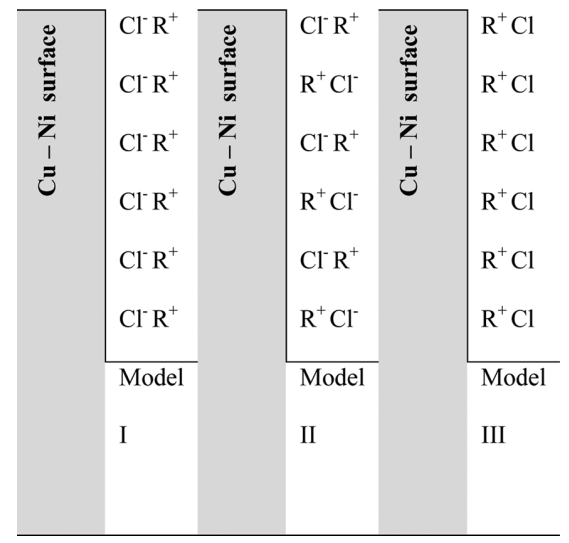

Fig. 10. Suggested inhibition models.

inhibitors cations $\left(\mathrm{R}^{+}\right)$from solution cluster around the chloride ions by columbic attraction on the metal surface where chloride ions are already adsorbed, then as a result tend to be weakly bound to the chloride ions, resulting in low coverage of the electrode surface. Model II represents a situation of weak adsorption of chloride ions; $\mathrm{R}^{+}$at high concentration tends to withdraw the chloride ions on the surface into the solution. Hence, co-adsorption of cations and chloride ions is possible as in model II, on increasing the concentration of inhibitors. The degree of desorption of chloride ions from the surface depends on the degree of adsorption of $\mathrm{R}^{+}$which is a function of the concentration of EDA and DETA. When the concentration of these inhibitors are increased, the chloride ions on the surface provide a better electrostatic condition, which promotes a direct adsorption of cations on the surface through its polar group, as seen in model III.

\section{Theoretical Calculations}

The optimized inhibitors molecules structures are shown in Fig. 11. Frontier orbital theory is useful in predicting adsorption centers of the inhibitor molecules responsible for the interaction with surface metal atoms. Terms involving the frontier MO could provide dominative contribution, because of the inverse dependence of stabilization energy on orbital energy difference. It has been reported in the literature that the higher the HOMO energy of the inhibitor, the greater the trend of offering electrons to unoccupied d orbital of the metal, and the higher the corrosion inhibition efficiency. In addition, the lower the LUMO energy, the easier the acceptance of electrons from metal surface, as the LUMO-HOMO energy gap decreased and the efficiency of inhibitor improved. ${ }^{33}$ Quantum chemical parameters listed in Table 5 reveal that 

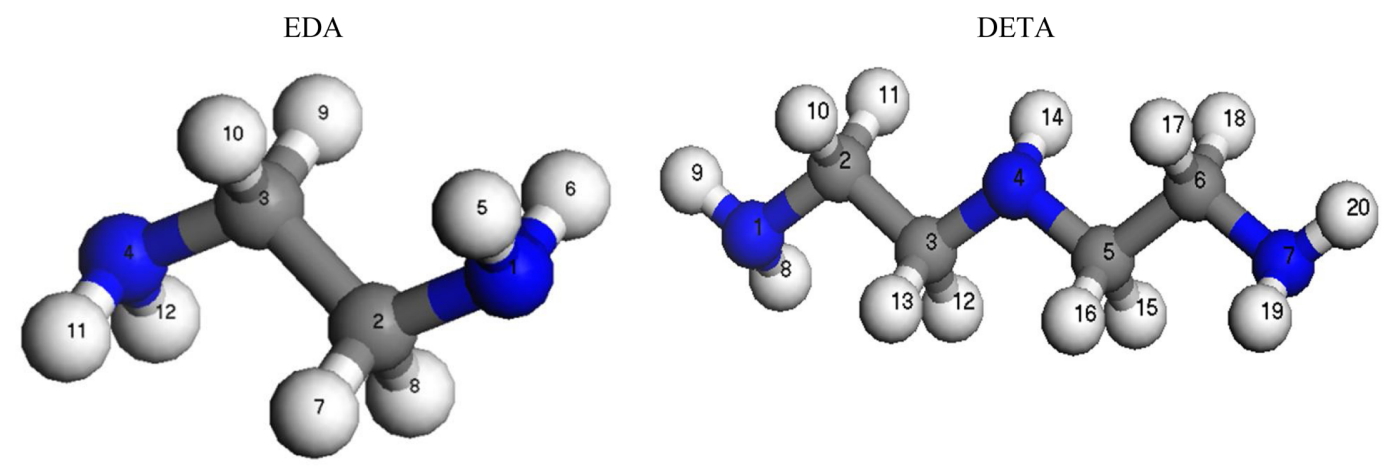

Optimized structure
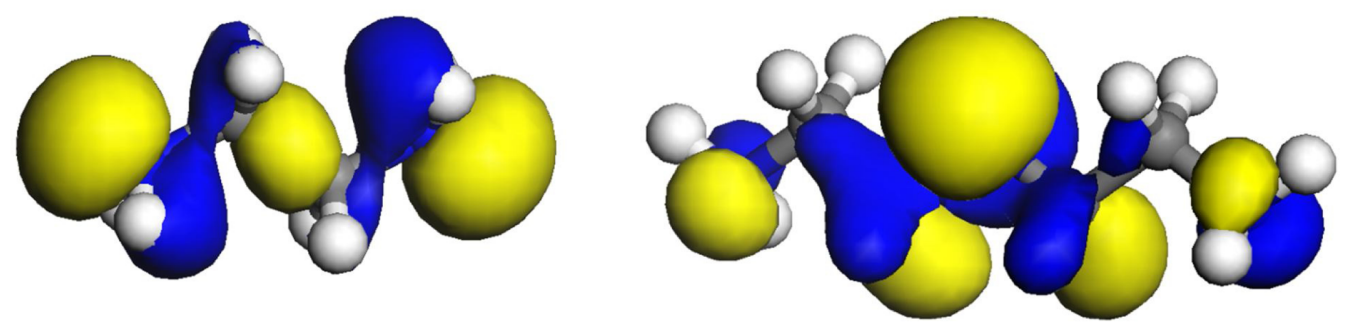

HOMO
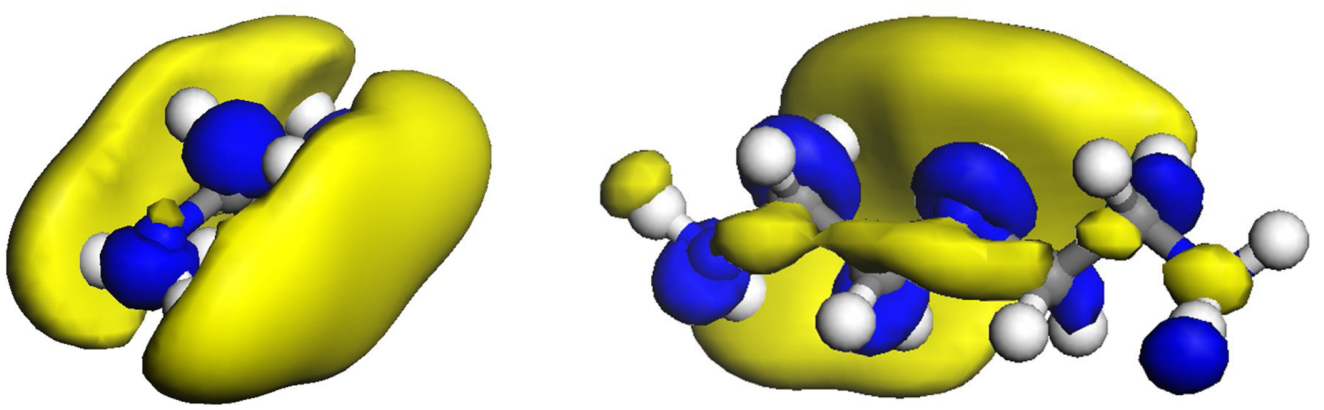

LUMO

Fig. 11. The frontier molecule orbital density distributions of EDA and DETA.

Table 5. Molecular properties of EDA and DETA calculated with DMol in Material Studio 5.5

\begin{tabular}{cccc}
\hline & $E_{\text {HOMO }}(\mathrm{eV})$ & $E_{\text {LUMO }}(\mathrm{eV})$ & $E_{\text {HOMO }}-E_{\text {LUMO }}(\mathrm{eV})$ \\
\hline EDA & -0.1787 & 0.0473 & -0.226 \\
DETA & -0.1773 & 0.0466 & -0.224 \\
\hline
\end{tabular}

EDA has higher HOMO with higher energy gap than DETA thus EDA exhibit more corrosion inhibition than DETA. In order to give further insight into the experimental results, ionization potentials are computed and the Fukui indices are used for predicting the preferential sites of electrophilic attack on both EDA and DETA. It is known that the Fukui indices were widely used as descriptors of site selectivity for the soft-soft reactions. ${ }^{34}$ According to Li-Evans, ${ }^{35}$ the favorite reactive site is that which possesses a high value of Fukui indices, thus we have cal-
Table 6. Fukui Indices for EDA and DETA calculated with DMol3 in Material Studio 5.5

\begin{tabular}{ccc}
\hline Inh. & Atoms & Fukui indices \\
\hline EDA & N1 & 0.196 \\
& N2 & 0.196 \\
\hline \multirow{3}{*}{ DETA } & N1 & 0.065 \\
& N4 & 0.196 \\
& N7 & 0.072 \\
\hline
\end{tabular}

culated the electrophilic Fukui indices $f_{k}^{-}$defined by Eq. 2 , for heteroatoms in systems. The results are given in Table 6. It turns out from the tabulated values that the nitrogen atoms (N1 and N2) in EDA possesses the largest value of Fukui indices while nitrogen atoms (N1 and N7) in DETA have small values of electrophilic Fukui indices, less than 0.08. Thus, the $\mathrm{N} 1$ and $\mathrm{N} 2$ atoms for EDA and $\mathrm{N} 4$ atom for DETA are more reactive for electrophilic 
attack. The addition of nitrogen atom in DETA does affect the Fukui indices in N1 atom by reducing its value to more than a half, however, N4 keep its value after the addition of nitrogen atom. These results seem to indicate that the $\mathrm{N} 4$ in both molecules, which has a great nucleophilic character, is involved in the chemical reactivity of these molecules with the metal surface.

\section{CONCLUSION}

The corrosion rate of $\mathrm{Cu}-\mathrm{Ni}$ alloy in $1.5 \mathrm{M} \mathrm{HCl}$ acid solution, increased with increase in temperature, and decreased with increase in inhibitors concentration. The values of activation parameters from Arrhenius equation and transition state equation in inhibited acid solution are significantly influenced by inhibitor concentration. The two suggested mathematical models were suitable to represent the corrosion rate data. Nonlinear regression analysis shows that the first model was better than the second model with high correlation coefficient. Reactive sites for nucleophilic and electrophilic attacks were indicated using the Fukui functions and located on the nitrogen atoms for both inhibitors. Results showed that the N4 in both molecules (EDA and DETA) involved in the chemical reactivity of these molecules with the metal surface.

Acknowledgments. The authors gratefully acknowledge Universiti Kebangsaan Malaysia (Grant No. UKMGGPM-NBT-037-2011) and University of Daiyla for the support of this work. Also special thank to Mrs. Areej S. Dawood for her assistance during this study.

\section{REFERENCES}

1. Fonsati, M.; Zucchi, F.; Trabanelli, G. Electrochim. Acta 1998, 44, 311.

2. Hosseini, M.; Mertens, S.F.L.; Ghorbani, M.; Arshadi, M. R. Mater. Chem. Phys. 2003, 78, 800 .

3. Queiroz Baddini, A. L.; de, Cardoso, S. P.; Hollauer, E., Cunha Ponciano Gomes, J. A. da Electrochim. Acta 2007, 53, 434.

4. Chetouani, A.; Daoudi, M.; Hammouti, B.; Ben Hadda, T.; Benkaddour, M. Corros. Sci. 2006, 48, 2987.

5. Tebbji, K.; Bouabdellah, I.; Aouniti, A.; Hammouti, B.; Oudda, H.; Benkaddour, M.; Ramdani, A. Mater. Lett. 2007, 61, 799.

6. Khalid, K. F. J. Appl. Electrochem. 2010, 40, 601.

7. Benali, O.; Larabi, L.; Mekelleche, S. M.; Harek, Y. J. Mater. Sci. 2006, 41, 7064.

8. Khadom, A. A.; Yaro, A. S.; Kadum, A. H.; Al Taie, A.
S.; Musa, A. Y. American Journal of Applied Sciences 2009, 6, 1403.

9. Khadom, A. A.; Yaro, A. S. Protection of Metals and Physical Chemistry of Surfaces Journal 2011, 47, 662.

10. El-Anadouli, B. E.; Ateya, B. G.; El-Nizamy, F. M. Corro. Sci. 1986, 26, 419.

11. Larabi, L.; Benali, O.; Mekelleche, S. M.; Harek, Y. Appl. Surf. Sci. 2006, 253, 1371.

12. Khadom, A. A.; Yaro, A. S.; Kadum, A. A. H. J. Taiwan Inst. Chem. Eng. 2010, 41, 122.

13. Noor, E. A.; Al-Moubaraki, A. H. Mater. Chem. Phys. 2008, 110, 145 .

14. Khadom, A. A.; Musa, A. Y.; Kadhum, A. H.; Abu Bakar Mohamad; Mohd Sobri Takriff Portugaliae Electrochimica Acta 2010, 28, 221.

15. Yaro, A. S.; Khadom, A. A.; Ibraheem, H. F. Anti-Corrosion Methods and Materials 2011, 58, 116.

16. Khadom, A. A.; Yaro, A. S.; Kadhum, A. H. J. Chil. Chem. Soc. 2010, 55, 150.

17. Khadom, A. A.; Yaro, A. S.; Al Taie, A. S.; Kadum, A. A. H. Portugalia Electrochemica Acta 2009, 27, 699.

18. Umoren, S. A.; Ebenso, E. E. Mater. Chem. Phys. 2007, 106, 387.

19. Umoren, S. A.; Obot, I. B.; Ebenso, E. E. E-journal of Chemistry 2008, 5, 355.

20. El-Awady, A. A.; Abd-El-Nabey, B. A.; Aziz, S. G. J. Electochem. Soc. 1992, 139, 2.

21. Mall, I. D.; Srivastava, V. C.; Agarwal, N. K.; Mishra, I. M. Colloids Surf., A: Physicochem. Eng. Asp. 2005, 264, 17.

22. Noor, E. A. J. Appl. Electrochem. 2009, 39, 1465.

23. Ali Doner; Ramazan Solmaz; Muzaffer Ozcan; Gulfeza Kardas Corros. Sci. 2011, 53, 2902.

24. Shams E1 Din, A. M.; E1 Dahshan, M. E.; Taj El Din, A. M. Desalination 2000, 130, 89.

25. Tromans, D.; Silva, J. C. J. Electrochem. Soc. 1996, 143, 458.

26. Zhang, D. Q.; Gao, L. X.; Zhou, G. D. Corros. Sci. 2004, 46, 3031.

27. Stupnisek-Lisac, E.; Brnada, A.; Mance, A. D. Corros. Sci. 2000, 42, 243.

28. Sherif, E. M.; Park, S. M. Electrochim. Acta 2006, 51, 6556.

29. Ma, H.; Chen, S.; Niu, L.; Zhao, S.; Li, S.; Li, D. J. Appl. Electrochem. 2002, 32, 65.

30. Kear, G.; Barker, B. D.; Walsh, F. C. Corros. Sci. 2004, 46, 109.

31. Khadom, A. A.; Yaro, A. S. Russian Journal of Physical Chemistry A 2011, 85, 2005.

32. E.E. Ebenso Mater. Chem. Phys. 2003, 79, 58.

33. Musa, A. Y.; Kadhum A. A. H.; Mohamad, A. B.; Rahoma, A. A.; Mesmari, H. J. Mol. Struct. 2010, 969, 233.

34. Geerlings, P.; De Proft, F. Int. J. Mol. Sci. 2002, 3, 276.

35. Li, Y.; Evans, J. N. J. Am. Chem. Soc. 1995, 117, 7756. 